\title{
THE EFFECT OF DIETARY LIPID LEVEL AND COMPOSITION ON GROWTH, SURVIVAL, AND DEVELOPMENT OF THE DIGESTIVE SYSTEM OF LARVAL SNEEP, CHONDROSTOMA NASUS (L.)
}

\author{
Teresa OSTASZEWSKA ${ }^{1 *}$, Agnieszka BORUTA ${ }^{2}$, Marta OLEJNICZAK $^{1}$ \\ ${ }^{1}$ Division of Ichthyobiology and Fisheries, ${ }^{2}$ Division of Animal Breeding and Production; Faculty of Animal Science, \\ Warsaw Agricultural University, Poland
}

Ostaszewska T., Boruta A., Olejniczak M. 2005. The effect of dietary lipid level and composition on growth, survival, and development of the digestive system of larval sneep, Chondrostoma nasus (L.). Acta Ichthyol. Piscat. 35 (2): 79-86.

Background. Rearing larval fish under laboratory conditions requires the use of appropriate artificial diets that fully replace natural food. Up till now, no starter has been developed for cyprinid rheophilic fish larvae, and these fish are therefore fed diets developed for other fish species. The present study was undertaken to evaluate the effects of diets of different protein-, lipid-, and fatty acid compositions on growth, survival, and changes in the digestive system during larval development of sneep (nase), Chondrostoma nasus (L.), from hatching until the juvenile stage.

Material and methods. From day 4 until day 21 post-hatch, sneep larvae were fed, Artemia nauplii and three starters: Nutra AB 3.0 (NU), Perla plus (PP), and Perla larva proactive (PL). Each experimental treatment was run in triplicate. On day 21 of the experiment, samples of fish were taken for size measurement, histological and morphometrical examination, and fatty acid analyses.

Results. The fish fed Artemia exhibited the highest growth rate and survival. Among the groups fed artificial diets, the highest survival and growth were observed in NU group, while PL group showed the worst results $(P<0.05)$. Comparison of the fatty acid composition in the diets and fish bodies revealed that the levels of n-3 PUFA were considerably higher in the bodies of fish fed starters than in the diets themselves, while concentrations of $n-6$ PUFA in the PP and PL groups were lower in fish than in diets. The NU diet showed the highest $n-3: n-6$ ratio (5.54), while PP had the lowest. The highest MUFA : PUFA ratio occurred in Artemia nauplii and the lowest in the PP diet. Histological observations revealed the presence of supranuclear lipid vacuoles in the enterocytes of the middle intestine section of Artemia-fed larvae. No such vacuoles were found in fish fed artificial diets. Morphological changes in the livers of fish fed various diets involved hepatocyte size and cytoplasm area containing glycogen and lipids.

Conclusions. Among the artificial diets, Nutra was the most appropriate for rearing sneep larvae. The results revealed that sneep larvae are capable of elongating and desaturating linolenic- and linoleic acids into longerchain fatty acids.

Key words: fish, Chondrostoma nasus, sneep, nase, diets, fatty acids, histology, intestine, liver

\section{INTRODUCTION}

Intensification of fish production requires knowledge of the effects of high-energy diets on the growth rate and time necessary to attain market size by the fish. Fish fed optimum and balanced diets should utilize lipids for energetic purposes. The results of studies on adult fish have shown that high dietary lipid level increases growth rate (Meer van der et al. 1997, Caballero et al. 1999). In the European sea bass (Dicentrarchus labrax), a diet containing 19\% lipid increased fish growth compared to diets with $11 \%$ and $15 \%$ lipid content (Lanari et al. 1999). However, the effect of dietary lipid level is different at various fish developmental stages. For instance, the growth rates of larval sea bass fed diets of 12\% to 20\% lipid content did not differ (Salhi et al. 1994). The optimum lipid content and appropriate fatty acid level for larval marine fish was determined by Sargent et al. (1999). For larval fish, polyunsaturated fatty acids (PUFA) are particularly important (Sargent et al. 1989). The n-3 PUFA positively affect growth and survival of larval marine fish (Izquierdo et al. 1992). According to Koven et al. (1992),

\footnotetext{
* Correspondence: Dr hab. Teresa Ostaszewska, prof. nadzw., Pracownia Ichtiobiologii i Rybactwa, Wydział Nauk o Zwierzętach, SGGW, ul. Ciszewskiego 8, 02-786 Warszawa, Poland, phone: (+48) 2259366 41, e-mail: ostaszewska@alpha.sggw.waw.pl
} 
the n-3 PUFA level plays the key role in fish feeding, while Bell et al. (1985) reported that high DHA : EPA ratio is of most importance. Data on the effects of lipid level and fatty acid composition in the diet on growth and development of freshwater fish are very scarce. Such studies were performed only for common carp (Cyrpinus carpio) (cf. Radünz-Neto et al. 1996, Fontagné et al. 1998), OnegaLake Atlantic salmon (Salmo salar) (cf. Yurovitskii et al. 1996), and white sturgeon (Acipenser transmontanus) (cf. Gawlicka et al. 2002). The present study was undertaken to evaluate the effects of diets of different lipid level and fatty acid composition on growth, survival, and changes in the digestive tract during larval development of the sneep (nase), Chondrostoma nasus (L.), from hatching until the juvenile stage. Sneep, as an endangered species, has recently become the object of studies in Poland and other European countries (Kamler et al. 1998, Keckeis et al. 2000), the aim of which has been development of artificial spawning and production techniques for restocking open waters (Wolnicki and Górny 1994). Therefore, the results of the presently reported study may be useful for determining the optimum conditions for rearing stocking material.

\section{MATERIAL AND METHODS}

Newly hatched sneep (nase), Chondrostoma nasus, larvae were obtained from the hatchery of the Experimental Fishery Station of the Warsaw Agriculture University in Łąki Jaktorowskie. The fish were placed in 20-L recirculation tanks at $20^{\circ} \mathrm{C}$ and a stocking density of 70 individuals per L. The fish were fed beginning 4 days post-hatch with no enriched Artemia nauplii or the starters Nutra AB 3.0 (NU), Perla plus (PP), or Perla larva proactive (PL) (Trouvit Nutreco Aqaculture, The Netherlands). Each experimental treatment was run in triplicate on these diets until 21 days post-hatch. Five larvae from each tank were then sampled for measurement of wet weight and total length, and for histological analyses. The fish were euthanised with an overdose of MS-222 (tricaine methanesulphonate). Total length was measured using a stereoscopic microscope to the nearest $0.01 \mathrm{~mm}$ and body weight to the nearest 0.01 , and then the larvae were preserved in Ciaccio and Bouin's solutions for histology using standard ethanol gradient dehydration and paraffin embedding. Series of 5-mm sections were obtained using a MicroTec CUT 4050 microtome. Larval morphology was examined in preparations stained with alcian blue-periodic acid Schiff reagent (AB/PAS) with $\mathrm{pH} 2.5$, 1.0 , and 0.5. PAS was used to stain for glycogen with diastase as a control. For lipid detection, the samples preserved in Ciaccio solution were stained with Sudan III (Martoja and Martoja-Pierson 1970, Pearse 1985). Cells were measured using a Nikon-Alphaphot-2YS2 microscope connected to a Nikon 4300 digital camera, and computer image analysis systems (MicroScan v. 1.5 and Lucia 4.21). Morphometric evaluation (hepatocyte area) and image analysis (measurements of the relative volume of intracellular lipid and glycogen deposits) were performed on 50 samples from each feeding group at $400 \times$ magnification. A total of $n=750$ measurements of each parameter were performed in feeding group. Survival was calculated as an average from three replicates $(n=3)$.

The presently reported study has been approved by the III Ethics Committee for the Experiments on Animals (at SGGW, Warsaw).

Measurements of fatty acid level. To evaluate fatty acid (FA) levels, fat was extracted from the fish using a modified method of Washburn and Nix (1974). FA separation and measurement was done using a HP 6890 gas chromatograph with BPX70 column. FA methyl esters were separated and the level of each acid expressed as a percentage of total FA content. The following FA methyl esters were identified:

saturated (SFA): C16:0, C18:0

monounsaturated (MUFA): C16:1, C18:1, C22:1

polyunsaturated (PUFA) n-3: C18:3, C20:5, C22:5, C22:6 (PUFA) n-6: C18:2, C20:3, C20:4.

Statistical analyses. The means $(\bar{x})$ and standard deviations $(s)$ were calculated for survival, fish body mass and length for each feeding group. The significance of differences among groups was tested using one-way ANOVA. The morphometric results were analysed using a one-way hierarchical ANOVA, taking into consideration the effects of feeding and individual variability within the groups. Significant differences were accepted at $P \leqslant 0.05$. All analyses were done using SPSS 12.

Table 1

Survival, body mass, and length of sneep larvae fed diets of differing lipid content and fatty acid composition $(\bar{x} \pm s)$

\begin{tabular}{lcccc}
\hline & \multicolumn{3}{c}{ Diet } \\
\cline { 2 - 5 } Parameter & $\begin{array}{c}\text { Artemia } \\
\text { nauplii } \\
\end{array}$ & Nutra & Perla plus & Perla larva \\
& $92 \pm 1^{\mathrm{d}}$ & $80 \pm 1^{\mathrm{c}}$ & $73 \pm 1^{\mathrm{b}}$ & $69 \pm 1^{\mathrm{a}}$ \\
\hline Survival* $[\%]$ & $(\mathrm{NU})$ & $(\mathrm{PP})$ & $(\mathrm{PL})$ \\
${\text { Body weight }[\mathrm{mg}]^{* *}}^{49 \pm 0.0014^{\mathrm{d}}}$ & $40 \pm 0.0012^{\mathrm{c}}$ & $33.3 \pm 0.0014^{\mathrm{b}}$ & $29 \pm 0.0013^{\mathrm{a}}$ \\
Standard length $[\mathrm{mm}]^{* *}$ & $19.3 \pm 0.32^{\mathrm{c}}$ & $18.5 \pm 0.31^{\mathrm{b}}$ & $18.3 \pm 0.32^{\mathrm{b}}$ & $17.2 \pm 0.27^{\mathrm{a}}$ \\
\hline
\end{tabular}

$* n=3 ; * * n=15$; values with different superscript letters are significantly different $(P \leqslant 0.05)$ 
Table 2 RESULTS

Composition of experimental diets (as \% of total fatty acid level)

\begin{tabular}{lcccc}
\hline & \multicolumn{4}{c}{ Diet } \\
\cline { 2 - 5 } & $\begin{array}{c}\text { Artemia } \\
(\mathrm{A})\end{array}$ & $\begin{array}{c}\text { Nutra } \\
(\mathrm{NU})\end{array}$ & $\begin{array}{c}\text { Perla } \\
\text { plus } \\
\text { (PP) }\end{array}$ & $\begin{array}{c}\text { Perla } \\
\text { larva } \\
(\mathrm{PL})\end{array}$ \\
\hline Nutritive value & 50 & 55 & 54 & 62 \\
Protein & 11 & 16 & 18 & 11 \\
Lipid & 8 & 12 & 10 & 10 \\
Ash & & & &
\end{tabular}

Fatty acid

composition

SFA

\begin{tabular}{|c|c|c|c|c|c|c|}
\hline & & $\mathrm{C} 12: 0$ & nd & 0.1 & 0.1 & 0.1 \\
\hline & & $\mathrm{C} 14: 0$ & 0.8 & 5.7 & 3.0 & 3.2 \\
\hline & & $\mathrm{C} 15: 0$ & nd & 0.5 & 0.3 & 0.4 \\
\hline & & $\mathrm{C} 16: 0$ & 10.4 & 16.2 & 17.0 & 16.6 \\
\hline & & $\mathrm{C} 17: 0$ & 1.5 & 0.4 & 0.3 & 0.4 \\
\hline & & $\mathrm{C} 18: 0$ & 5.2 & 2.8 & 3.9 & 3.9 \\
\hline & & $\mathrm{C} 20: 0$ & nd & 0.2 & 0.2 & 3.3 \\
\hline & & $\mathrm{C} 22: 0$ & nd & 0.1 & 0.2 & 0.2 \\
\hline & & $\mathrm{C} 24: 0$ & nd & 0.2 & 0.2 & 0.2 \\
\hline MUFA & & & 44.7 & 38.7 & 27.0 & 28.5 \\
\hline & & $\mathrm{C} 14: 1$ & nd & 0.2 & 0.1 & 0.1 \\
\hline & & C16:1 & 13.2 & 6.1 & 3.4 & 3.6 \\
\hline & & $\mathrm{C} 17: 1$ & nd & 0.2 & 0.2 & 0.2 \\
\hline & & C18:1 & 28.5 & 14.7 & 14.4 & 14.5 \\
\hline & & $\mathrm{C} 20: 1$ & nd & 6.9 & 3.5 & 3.5 \\
\hline & & $\mathrm{C} 22: 1$ & 3.0 & 10.0 & 4.8 & 5.8 \\
\hline & & $\mathrm{C} 24: 1$ & nd & 0.6 & 0.6 & 0.8 \\
\hline PUFA & & & 31.5 & 32.7 & 46.3 & 44.7 \\
\hline & & $\mathrm{n}-3$ & 17.6 & 27.7 & 24.9 & 25.3 \\
\hline & & $n-6$ & 13.9 & 5.0 & 21.4 & 19.4 \\
\hline & & $C 16: 2 n-6$ & nd & 0.4 & 0.5 & 0.4 \\
\hline & & $C 16: 3 n-6$ & 1.9 & 0.6 & 0.2 & 0.3 \\
\hline & & C16:4 n-6 & nd & 0.4 & 0.2 & 0.2 \\
\hline & LA & $\mathrm{C} 18: 2 \mathrm{n}-6$ & 9.6 & 2.6 & 19.2 & 16.8 \\
\hline & LNA & C18:3 n-3 & 3.8 & 1.0 & 3.1 & 2.9 \\
\hline & & C18:4 n-3 & 0.7 & 3.0 & 2.1 & 1.8 \\
\hline & & $\mathrm{C} 20: 2 \mathrm{n}-6$ & nd & 0.2 & 0.2 & 0.2 \\
\hline & & C20:3 n-6 & nd & 0.1 & 0.1 & 0.1 \\
\hline & $\mathrm{AA}$ & C20:4 n-6 & 2.4 & 0.6 & 0.9 & 1.3 \\
\hline & EPA & $C 20: 5 n-3$ & 13.1 & 9.8 & 6.6 & 7.1 \\
\hline & & $\mathrm{C} 22: 4 \mathrm{n}-6$ & nd & 0.1 & 0.1 & 0.1 \\
\hline & & $\mathrm{C} 22: 5 \mathrm{n}-3$ & nd & 1.1 & 0.9 & 1.2 \\
\hline & DHA & $\mathrm{C} 22: 6 \mathrm{n}-3$ & nd & 12.8 & 12.2 & 12.3 \\
\hline MUFA & JFA & $n-3: n-6$ & $\begin{array}{l}1.42 \\
1.27\end{array}$ & $\begin{array}{l}1.18 \\
5.54\end{array}$ & $\begin{array}{l}0.58 \\
1.16\end{array}$ & $\begin{array}{l}0.64 \\
1.30\end{array}$ \\
\hline
\end{tabular}

nd, not detected; artificial diets also contain: vitamins $\left(\mathrm{A}, \mathrm{D}_{3}, \mathrm{E}\right.$, $\left.\mathrm{B}_{1}, \mathrm{~B}_{2}, \mathrm{~B}_{6}, \mathrm{~B}_{12}, \mathrm{PP}, \mathrm{C}, \mathrm{K}\right)$
Survival, growth, and fatty acid analysis. Survival and growth rates differed significantly among diets, being highest in the Artemia-fed fish and lowest in the PL-fed fish (Table 1). No tank effect was observed.

The four diets differed in protein- $(50 \%-62 \%)$, lipid$(11 \%-18 \%)$, and fatty acid composition (Table 2). Comparison with body composition (Table 3) revealed that the saturated fatty acid (SFA) content of fish fed PP, NU, and PL diets was lower than in the diets themselves, whereas the SFA level in Artemia-fed larvae was higher than in the Artemia nauplii. The percentage of monounsaturated fatty acids (MUFAs) was higher in NU, PL, and Artemia than in the fish bodies. In the PP group, on the other hand, the MUFA level was higher in the fish than in the diet. The polyunsaturated fatty acid (PUFA) content in fish bodies was much higher than in the diets in the NU and PL groups, while in the PP and Artemia groups the levels were similar in both fish and diets. The PP-, NU-, and PL-fed fish showed much higher concentrations of n3 PUFA than in the diets, while in Artemia-fed fish their concentrations were lower than in the nauplii. The n-6 PUFA levels were lower in the bodies of fish fed PP and PL, and higher in larvae fed NU and Artemia, compared to their diets. The highest $n-3: n-6$ ratio (5.54) occurred in the NU diet and the lowest in the PP diet. The MUFA : PUFA ratio was highest in Artemia nauplii, and lowest in PP diet (Table 2).

Histological analyses. The intestines of all larvae were developing correctly (Fig. 1a-d). In the Artemia-fed

Table 3

Whole-body fatty acid composition of larval sneep fed Artemia nauplii or commercial diets (as \% of total fatty acid level)

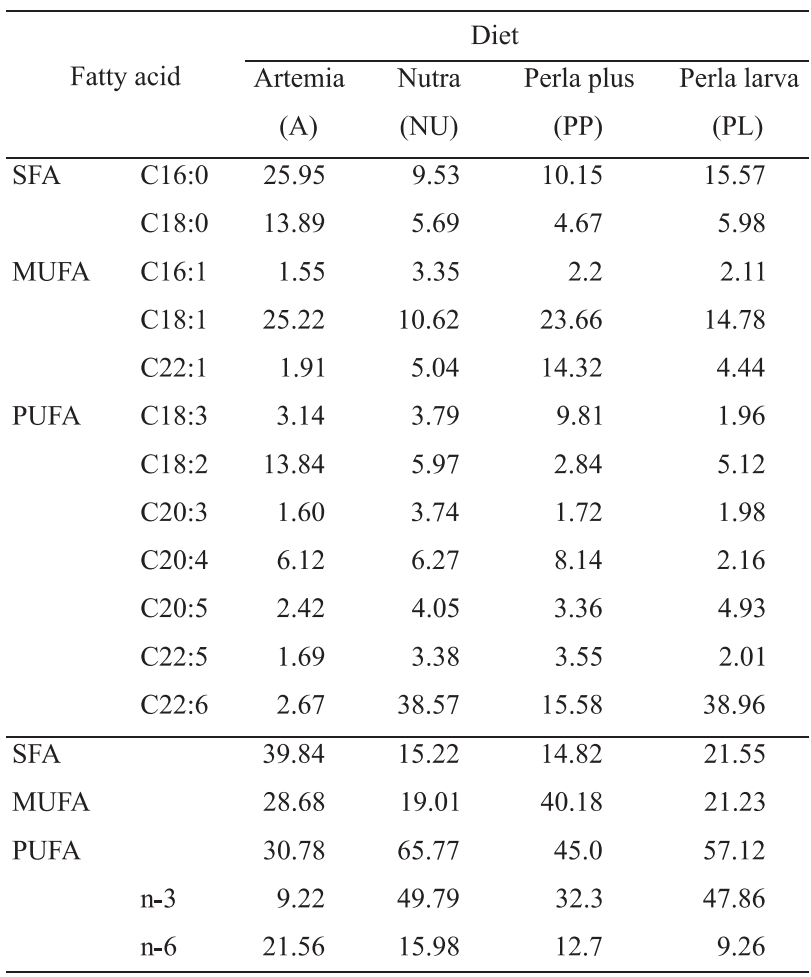



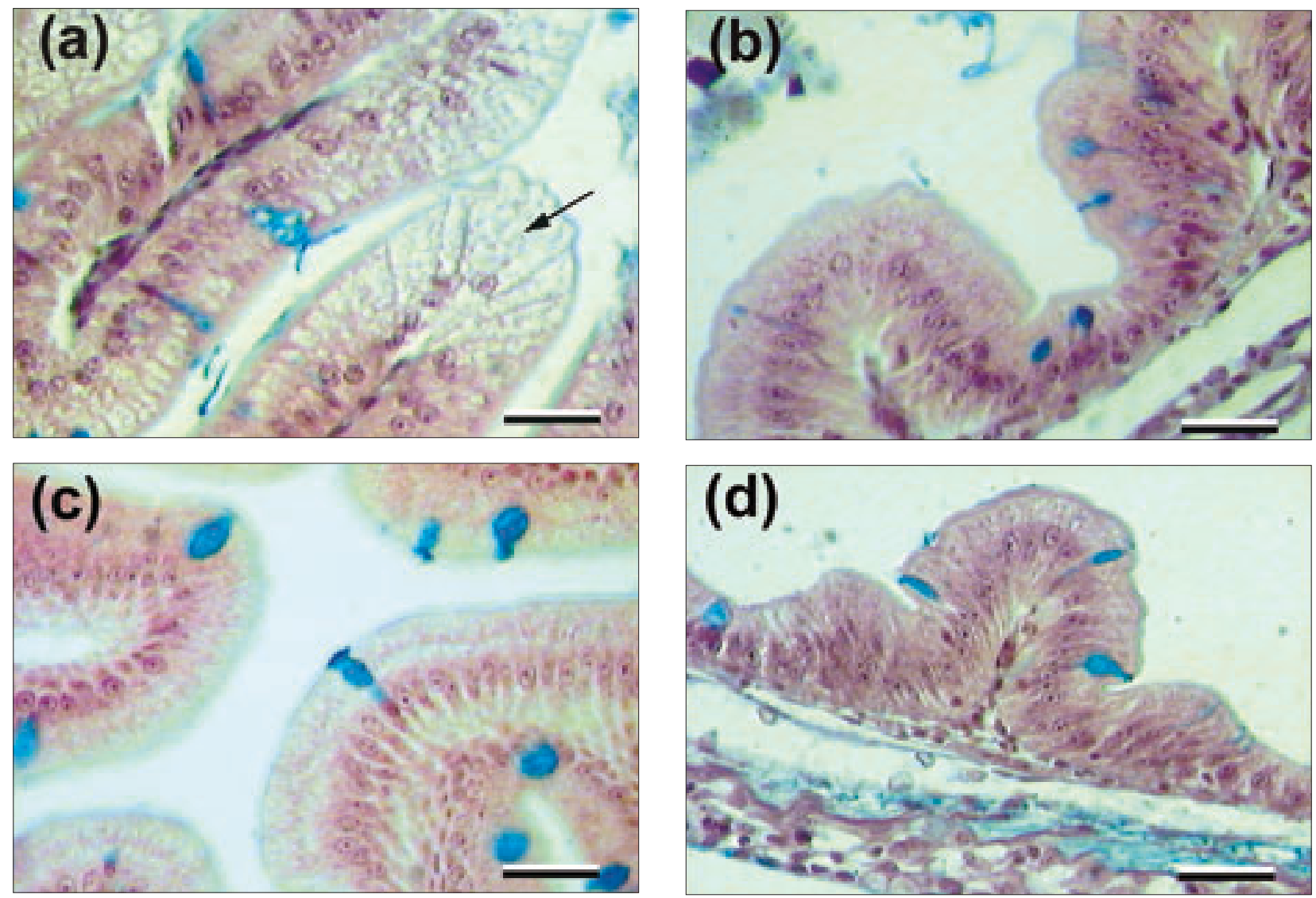

Fig. 1. Longitudinal sections of the middle intestine folds of sneep larvae fed different experimental diets: a) Artemia nauplii-lipid vacuoles in the supranuclear regions of enterocytes (arrow); b) Nutra; c) Perla plus; d) Perla larva; staining AB/PAS; scale bar $=25 \mu \mathrm{m}$
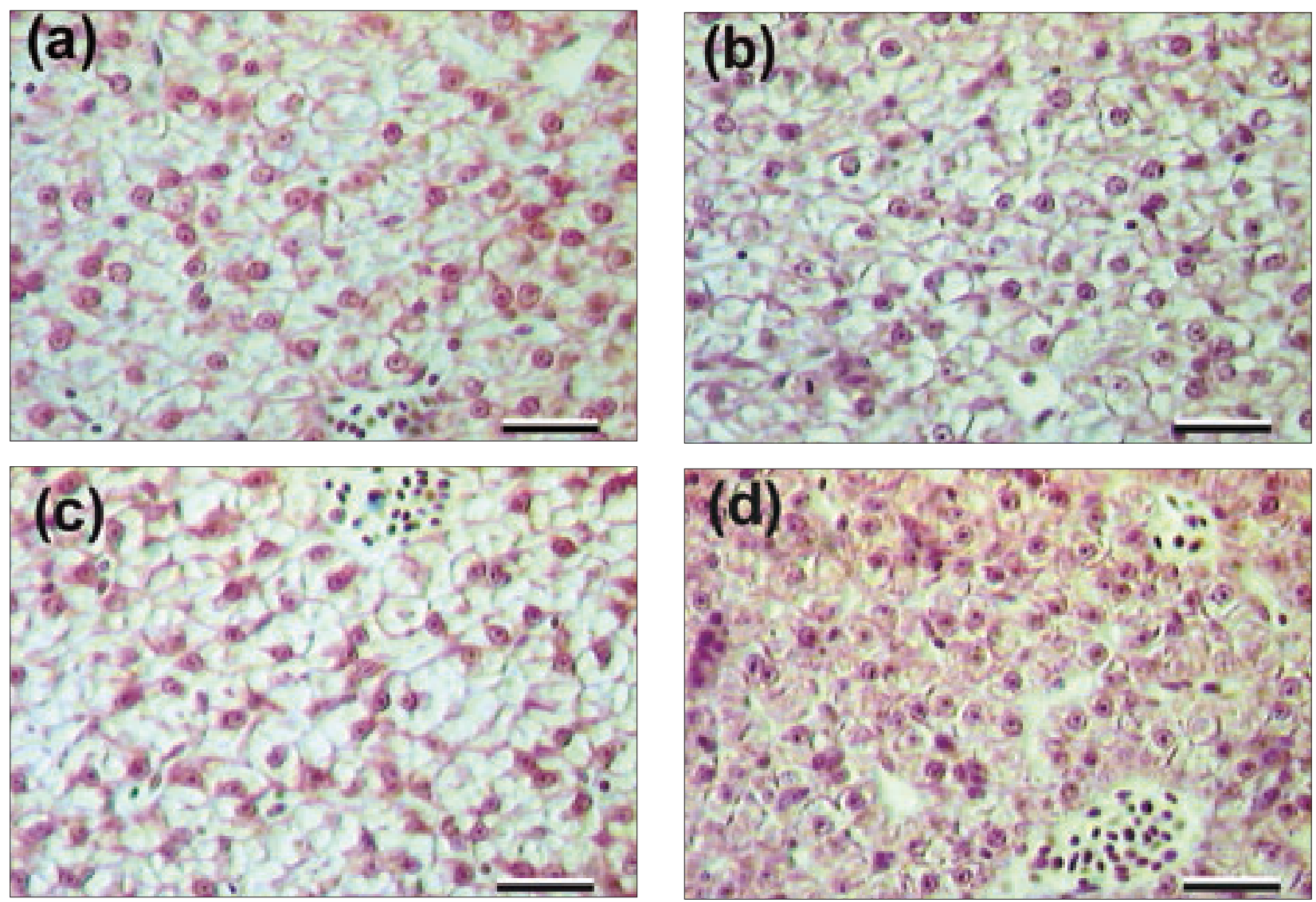

Fig. 2. Hepatocytes of sneep larvae fed: a) Artemia nauplii; b) Nutra; c) Perla plus; d) Perla larva; staining AB/PAS; scale bar = $25 \mu \mathrm{m}$ 


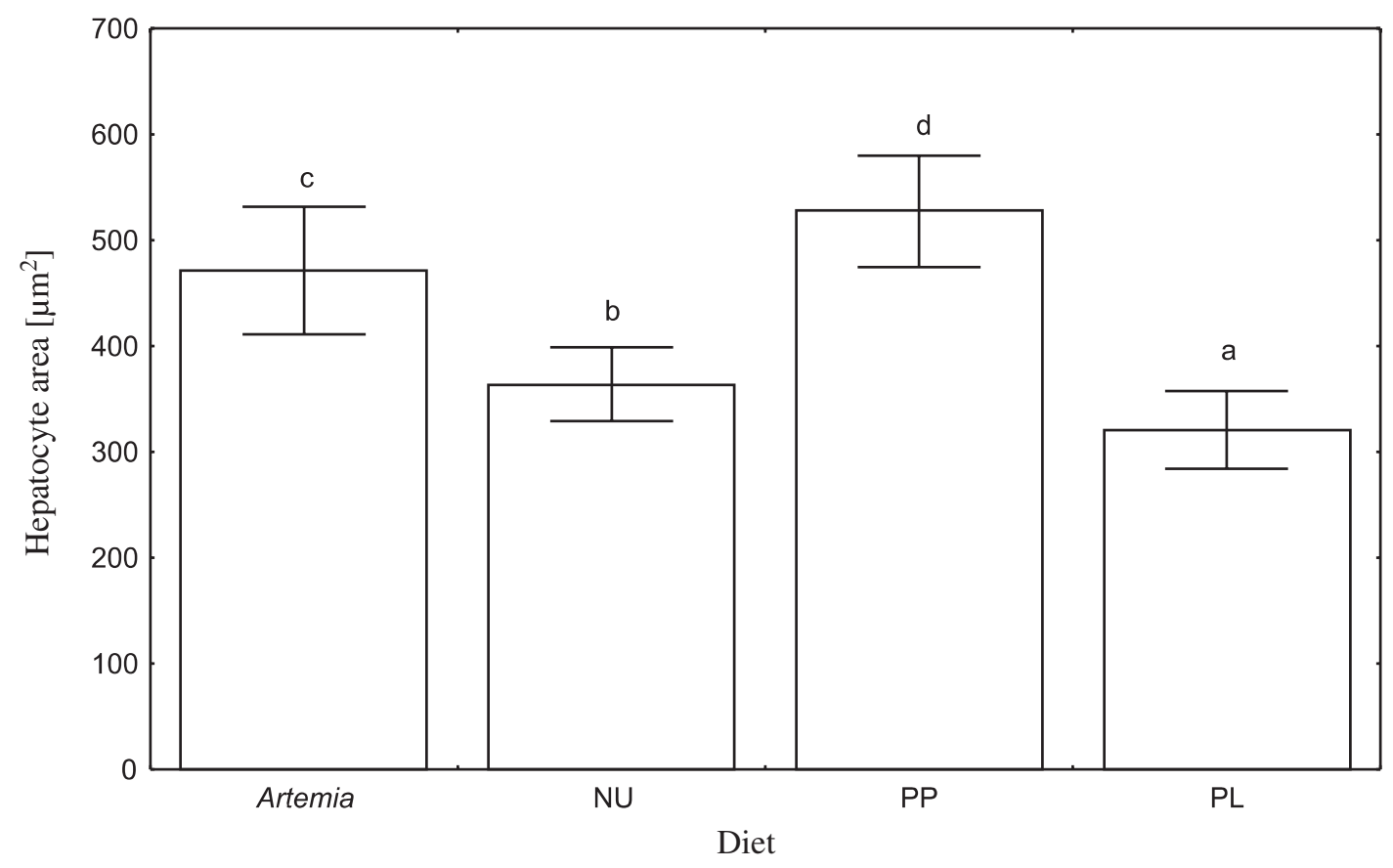

Fig. 3. Hepatocyte area $(\bar{x} \pm s, n=750)$ in sneep larvae fed Artemia nauplii and artificial diets; values with different letters are significantly different $(P<0.05)$

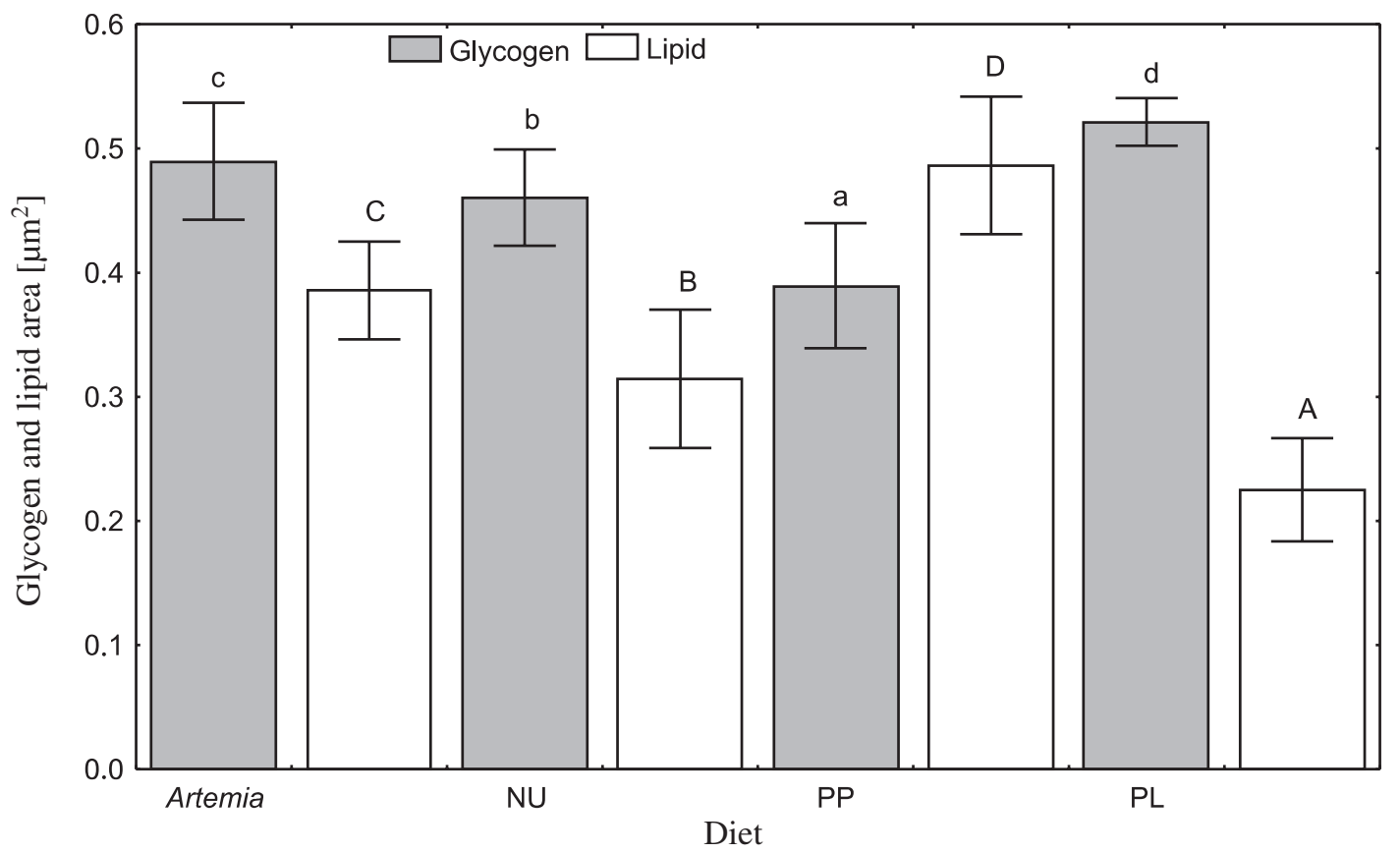

Fig. 4. The average relative volume $(\bar{x} \pm s, n=750)$ of hepatocyte glycogen and lipid deposits; values with different letters are significantly different $(P<0.05)$

fish, supranuclear regions of middle intestine enterocytes contained Sudan III-staining lipid vacuoles (Fig. 1a). No such vacuoles were observed in the other experimental groups (NU, PP, and PL) (Fig. 1b-d). Histological analyses of the livers revealed hepatocyte changes in fish fed PP- and PL diets, comparing to those fed Artemia nauplii and NU starter (Fig. 2a-d). In the larvae fed Artemia and $\mathrm{NU}$, hepatocytes had a firm structure and were tightly joined (Fig. 2a, b). Their nuclei were centrally located and had centrally located nucleoli. They also had similar lipid and glycogen levels (Figs. 2a, 2b, 4). Glycogen deposition was considerably reduced in the hepatocytes of PP-fed fish, while the number and size of lipid vacuoles was much higher compared to the glycogen storage regions (Figs. 2c, 4). Hepatocytes of PP-fed fish were also significantly larger compared to the other groups (Fig. 3; $P<0.05$ ). The hepatocytes of fish fed the PL diet were smaller $(P<0.05)$ than in the other groups (Figs. 2d, 3). Their cytoplasm con- 
tained larger glycogen areas compared to the lipid vacuoles (Figs. 2d, 4)

\section{DISCUSSION}

The results of this study show that among the artificial diets, Nutra (NU) was the most appropriate for feeding sneep larvae. The larvae fed this diet had the highest survival and growth, although inferior to that obtained with Artemia nauplii. Morphological observations also revealed correct development, digestion, and nutrient absorption by the NU-fed fish. High dietary fat content reduces de novo fatty acid synthesis by inhibiting the activity of various hepatic lipogenic enzymes, such as acetyl coenzyme A carboxylase, fatty acid synthetase, glucose-6-phosphate dehydrogenase, and 6-phosphogluconate dehydrogenase (Sargent et al. 1989). The high fat level of the Perla plus diet probably disturbed enzyme synthesis, resulting in a high MUFA level and the observed changes in liver structure. Sneep larvae fed this diet had the largest hepatocytes and the largest relative lipid area in their cytoplasm. Similar hepatocyte changes induced by excessive dietary lipid content or inappropriate fatty acid composition have been observed in yellow perch, Perca flavescens (cf. Brown et al. 1996), rainbow trout, Oncorhynchus mykiss (cf. Yang and Dick 1994), and sea trout, Salmo trutta (cf. Arzel et al. 1994).

According to Yang and Dick (1994), hepatic fat deposition is a result of essential fatty acid deficiency. The presence of lipid vacuoles in the enterocytes of fish fed Artemia nauplii was probably related to the excessive lipid supply or disturbances in lipid metabolism. This may be explained as temporary storage of fatty acid reesterification products, which may be accumulated when the export ability of enterocytes is exceeded. Lipid storage in the enterocytes of fish fed Artemia nauplii probably reduced the rate of chylomicron and VLDL (very low density lipoprotein) transport from the intestine to the liver. Similar lipid vacuoles in larvae fed Artemia were observed by Deplano et al. (1991) and Verreth et al. (1992).

It should be stressed that Artemia nauplii are not the natural food of sneep larvae. The sneep is a phytophagous fish feeding mainly on phytoplankton but also on insects. Freshwater phytoplankton contains mainly C18:3 n-3, C18:2 n-6, and C22:6 n-3 PUFAs (Ahlgren et al. 1992), while freshwater invertebrates contain mainly C18:3n-3, C18:2n-6, and C20:5n-3 (Bell et al. 1994). Artemia nauplii do not meet the nutritional requirements of fish larvae due to insufficient PUFA levels, particularly of the n-3 variety (Lavens et al. 1995). On the other hand, Artemia nauplii are live food providing fish with digestive enzymes that facilitate digestion in the youngest larval stages (Kolkovski et al. 1993). This likely explains why the larvae fed Artemia showed the highest survival and growth rates.

The C16:0, C18:1 n-9, C20:1 n-9, and C22:1 n-11 fatty acids are mainly catabolysed for energetic purposes. High amounts of all these acids are consumed during fish growth and development, and they are easily catabolysed by the mitochondrial $\beta$-oxidation (Henderson 1996).
Increased area and number of lipid vacuoles in the hepatocytes of fish fed Artemia and PP probably resulted from the excessive supply of SFA and MUFA, the excess of which was not utilised for energy production and therefore accumulated in liver.

The essential fatty acid (EFA) requirement of sneep larvae is unknown; it differs among species and depends upon water temperature and salinity (Anonymous 1993). Rainbow trout need C18:3 n-3 rather than C18:2 n-6 (Castell et al. 1972), while common carp and Japanese eel (Anguilla japonica) need a mixture of C18:3 n-3 and C18:2 n-6 (Takeuchi et al. 1980, Radünz-Neto et al. 1996) and redbelly tilapia (Tilapia zillii) require only C18:2 n-6 (Kanazawa et al. 1980). EFA requirements have been determined for very few freshwater fish larvae, e.g. common carp (RadünzNeto et al. 1996) and rainbow trout (Wirth et al. 1997).

According to Bell et al. (1986), C18:3 n-3 and C18:2 n-6 fatty acids play an important role in freshwater fish as substrates for PUFA synthesis. In many freshwater fish species, the conversion of linolic acid (C18:2n-6; LA) to arachidonic acid (20: 4 n-6; AA), and of linolenic acid (C18:3 n-3; LNA) to eicosapentaenoic (C20:5 n-3; EPA) and docosahexaenoic acid (C22:6 n-3; DHA) has been observed (Sargent et. al. 1995). Rainbow trout larvae do not show an ability to convert C18:3 n-3 or C18:4 n-3 to $\mathrm{C} 22: 6 \mathrm{n}-3$, which indicates that $\mathrm{C} 22: 6 \mathrm{n}-3$ is essential for them (Wirth et al. 1997). Tilapia larvae fed rotifer Brachionus calyciflorus with addition of various microalgae containing only C18:3 n-3 and C18:2 n-6 PUFA show a low level of C18 PUFA and high level of C22:6 n-3, which indicates that these larvae easily convert C18 FA to PUFA (Isik et al. 1999).

The results of present study indicate that sneep larvae may also convert C18:3 n-3 to C20:5 n-3 and C22:6 n-3. Similarly, young stages of a phytophagous piranha, Mylossoma aureum, easily convert C18:2 n-6 to C20:4 n-6, and C18:3 n-3 to C20:5 n-3 and C22:6 n-3 (Henderson et al. 1996).

The bodies of all larvae contained higher levels of AA (arachidonic acid) and DHA compared to the levels of these acids in diets, which indicates that these acids are important for correct growth and development of sneep larvae (Montero et al. 2001). AA and EPA acids are incorporated into the cell membrane structures. The 20C acids are the source of eicosanoids, which are important tissue hormones.

According to Spisni et al. (1998), lipid accumulation in the livers of gilthead seabream (Sparus aurata) and European seabass (Dicentrarchus labrax) resulted from a low MUFA: PUFA ratio. The results of the present study confirm this supposition: the PP diet had the lowest MUFA : PUFA ratio, and larvae fed this diet showed the highest lipid storage in hepatocyte cytoplasm. The hepatocytes of these fish also showed reduced glycogen storage and abundant lipid vacuoles. Hepatic fat deposition (steatosis) was described as a disturbance resulting from an excessive or unbalanced supply of dietary lipids exceeding the physiological lipid conversion ability of 
liver, which results in hepatic lipid accumulation as fat drops (triglycerides) and hepatocyte enlargement (Spisni et al. 1998). The lowest hepatocyte volume and lipid content was observed in fish fed Perla larva. This group also had the lowest survival and body mass, which probably resulted from insufficient dietary lipid content. Slow growth of sneep larvae fed PL and PP diets might have been related to much higher C18:2 n-6 levels in these diets compared to the Artemia nauplii and NU starter. Excessive dietary C18:2 n-6 also reduced the growth of rainbow trout (Yu and Sinnhuber 1975).

\section{ACKNOWLEDGEMENTS}

The presently reported study was financed by the State Committee for Scientific Research (KBN), Poland (grant No. 3 PO6Z 02724 (2003/06).

\section{REFERENCES}

Ahlgren G., Gustafsson I.-B., Boberg M. 1992. Fatty acid content and chemical composition of freshwater microalgae. Journal of Phycology 28: 37-50.

Anonymous 1993. Nutrient requirements of fish. Committee on Animal Nutrition; Board on Agriculture; National Research Council; National Academy Press, Washington, DC.

Arzel J., Martinez Lopez F.X., Métailler R., Stéphan G., Gandemer G., Guillaume J. 1994. Effect of dietary lipid on growth performance and body composition of brown trout (Salmo trutta) reared in seawater. Aquaculture 123: 361-375.

Bell J.G., Ghioni C., Sargent J.R. 1994. Fatty acid composition of 10 freshwater invertebrates which are natural food organisms of Atlantic salmon parr (Salmo salar): a comparison with commercial diets. Aquaculture 128: 301-313.

Bell M.V., Henderson R.J., Pirie B.J.S., Sargent J.R. 1985. Effect of dietary polyunsaturated fatty acid deficiencies on mortality, growth and gill structure in the turbot, Scopthalmus [sic] maximus. Journal of Fish Biology 26: 181-191.

Bell M.V., Henderson R.J., Sargent J.R. 1986. The role of polyunsaturated fatty acids in fish. Comparative Biochemistry and Physiology B 83: 711-719.

Brown P.B., Dabrowski K., Garling D.L. 1996. Nutrition and feeding of yellow perch (Perca flavescens). Journal of Applied Ichthyology 12: 171-174.

Caballero M.J., López-Calero G., Socorro J., Roo F.J., Izquierdo M.S., Férnandez A.J. 1999. Combined effect of lipid level and fish meal quality on liver histology of gilthead seabream (Sparus aurata). Aquaculture 179: 277-290.

Castell J.D., Sinnhuber R.O., Wales J.H., Lee J.D. 1972. Essential fatty acids in the diet of rainbow trout (Salmo gairdneri): growth, feed conversion and some gross deficiency symptoms. Journal of Nutrition 102: 77-86.

Deplano M., Diaz J. P., Connes R., Kentouri-Divanach M., Cavalier F. 1991. Appearance of lipid absorption capacities in larvae of the sea bass Dicentrarchus labrax L., during transition to the exotrophic phase. Marine Biology 108: 361-371.

Fontagné S., Geurden I., Escarffe A.-M., Bergot P. 1998. Histological changes induced by dietary phospholipids in intestine and liver of common carp (Cyprinus carpio L.) larvae. Aquaculture 161: 213-223.

Gawlicka A., Herold A.M., Barrows F.T., Noüe de la J., Hung S.S.O. 2002. Effect of dietary lipids on growth, fatty acid composition, intestinal absorption and hepatic storage in white sturgeon (Acipenser transmontanus R.) larvae. Journal of Applied Ichthyology 18: 673-681.

Henderson R.J. 1996. Fatty acid metabolism in freshwater fish with particular reference to polyunsaturated fatty acids. Archives of Animal Nutrition 49: 5-22.

Henderson R.J., Tillmanns M.M., Sargent J.R. 1996. The lipid composition of two species of serrasalmid fish in relation to dietary polyunsaturated fatty acids. Journal of Fish Biology 48: 522-538.

Isik O., Sarihan E., Kusvuran E., Gul O., Erbatur O. 1999. Comparison of the fatty acid composition of the freshwater fish larvae Tilapia zillii, the rotifer Brachionus calyciflorus, and the microalgae Scenedesmus abundans, Monoraphidium minitum and Chlorella vulgaris in the algae-rotifer-fish larvae food chains. Aquaculture 174: 299-311.

Izquierdo M.S., Arakawa T., Takeuchi T., Haroun R., Watanabe T. 1992. Effect of $n-3$ HUFA levels in Artemia on growth of larval Japanese flounder (Paralicthys olivaceus). Aquaculture 105: 73-82.

Kamler E., Keckeis H., Buer-Nemeschkal E. 1998. Temperature-induced changes of survival, development and yolk partitioning in Chondrostoma nasus. Journal of Fish Biology 53: 658-682.

Kanazawa A., Teshima S.I., Sakamoto M., Awal Md. A. 1980. Requirements of Tilapia zillii for essential fatty acids. Bulletin of the Japanese Society of Scientific Fisheries (Nippon Suisan Gakkaishi) 46: 1353-1356.

Keckeis H., Bauer-Nemeschkal E., Menshutkin V.V., Nemeschkal H.L., Kamler E. 2000. Effects of female attributes and egg properties on offspring viability in a rheophilic cyprinid, Chondrostoma nasus. Canadian Journal of Fisheries and Aquatic Sciences 57: 789-796.

Koven W.M., Tandler A., Kissil G.W., Sklan D. 1992. The importance of $n-3$ highly unsaturated fatty acids for growth in larval Sparus aurata and their effect on survival, lipid composition and size distribution. Aquaculture 104: 91-104.

Kolkovski S., Tandler A., Kissil G.W., Gertler A. 1993. The effect of dietary exogenous digestive enzymes on ingestion, assimilation, growth and survival of gilthead seabream (Sparus aurata) larvae. Fish Physiology and Biochemistry 12: 203-209.

Lanari D., Poli M.B., Ballestrazzi R., Lupi P., D'Agaro E., Mecatti M. 1999. The effects of dietary fat and NFE levels on growing European sea bass (Dicentrarchus labrax L.). Growth rate, body and fillet composition, carcass traits and nutrient retention efficiency. Aquaculture 179: 351-364.

Lavens P., Sorgeloos P., Dhert Ph., Devresse B. 1995. Larval foods. pp. 373-397. In: Bromage N.R., Roberts R.J. (eds.) Broodstock management and egg and larval quality. Blackwell Science Ltd., Oxford.

Martoja R., Martoja-Pierson M. 1970. Técnicas de histologia animal. Toray Masson S.A., Barcelona.

Meer van der M.B., Zamora J.E., Verdegem M.C.J. 1997. Effect of dietary lipid level on protein utilization and the size 
proximate composition of body compartments of Colossoma macropomum (Cuvier). Aquaculture Research 28: 405-417.

Montero D., Robaina L.E., Socorro J., Vergara J.M., Tort L., Izquierdo M.S. 2001. Alteration of liver and muscle fatty acid composition in gilthead seabream (Sparus aurata) juveniles held at high stocking density and fed an essential fatty acid deficient diet. Fish Physiology and Biochemistry 24: 63-72.

Pearse A.G.E. 1985. Histochemistry. Theoretical and applied. Vol. 2. Analytical Technology. Churchill Livingstone, Edinburgh.

Radünz-Neto J., Corraze G., Bergot P., Kaushik S.J. 1996. Estimation of essential fatty acid requirements of common carp larvae using semi-purified artificial diets. Archiv für Tierernährung 49: 41-48.

Salhi M., Izquierdo M.S., Hernandez-Cruz C.M., Gonzalez M., Fernandez-Palacios H. 1994. Effect of lipid and n-3 HUFA levels in microdiets on growth, survival and fatty acid composition of larval gilthead seabream (Sparus aurata). Aquaculture 124: 275-282.

Sargent J.R, Bell J.G., Bell M.V., Henderson R.J., Tocher D.R. 1995. Requirement criteria for essential fatty acids. Journal of Applied Ichthyology 11: 183-198.

Sargent J.R, Bell G., McEvoy L., Tocher D., Estevez A. 1999. Recent developments in the essential fatty acid nutrition of fish. Aquaculture 177: 191-199.

Sargent J.R., Henderson R.J., Tocher D.R. 1989. The lipids. pp. 153-218. In: Halver J.E. (ed.) Fish nutrition, 2nd edn. Academic Press, San Diego, CA.

Spisni E., Tugnoli M., Ponticelli A., Mordenti T., Tomasi V. 1998. Hepatic steatosis in artificially fed marine teleosts. Journal of Fish Diseases 21: 177-184.

Takeuchi T., Arai S., Watanabe T., Shimma Y. 1980. Requirement of eel Anguilla japonica, for essential fatty acids. Bulletin of the Japanese Society of Scientific Fisheries (Nippon Suisan Gakkaishi) 46: 345-353.

Verreth J., Torreele E., Spazier E., van der Sluiszen A., Rombout J., Booms R., Segner H. 1992. The development of a functional digestive system in the African catfish Clarias gariepinus (Burchell). Journal of World Aquaculture Society 23: 286-298.

Washburn K.W., Nix D.F. 1974. Genetic basis of yolk cholesterol content. Poultry Science 53: 109-115.

Wirth M., Steffens W., Meinelt T., Steinberg C. 1997. Significance of docosahexaenoic acid for rainbow trout (Oncorhynchus mykiss) larvae. Lipid-Fett 99: 251-253.

Wolnicki, J., Górny W. 1994. Odchów wylęgu świnki (Chondrostoma nasus L.) w warunkach kontrolowanych. Cz. 1: Przebieg i wyniki. [Rearing of nase (Chondrostoma nasus L.) under controlled conditions. Part I. Course and results.] Komunikaty Rybackie 3: 6-7. [In Polish.]

Yang X., Dick T.A. 1994. Artcic charr (Salvelinus alpinus) and rainbow trout (Oncorhynchus mykiss) differ in their growth and lipid metabolism in response to dietary polyunsaturated fatty acids. Canadian Journal of Fisheries and Aquatic Sciences 51: 1391-1400.

Yu T.C., Sinnhuber R.O. 1975. Effect of dietary linolenic and linoleic acids on growth and lipid metabolism of rainbow trout (Salmo gairdneri). Lipids 10: 63-66.

Yurovitskii Yu.G., Nefedova Z.A., Sidorov V.S. 1996. Dynamics of lipid content in the salmon embryos and larvae. Russian Journal of Developmental Biology 27: 74-78.

Received: 24 August 2005 Accepted: 10 November 2005 